

\title{
Ergonomic evaluation of rural and urban kitchen design of Muzaffarpur district in Bihar
}

\author{
Nikhat parveen and Shishir Kala
}

Received: 04.09.2018; Revised: 05.04.2019; Accepted: 15.04.2019

See end of the paper for authors' affiliations

Nikhat parveen

Department of Family Resource

Management, C.C.S., Rajendra

Prasad Central Agricultural

University Pusa, Samastipur

(Bihar) India

Email : nikhatp61@gmail.com
ABSTRACT : Ergonomic designed kitchen has become the need of almost all the women keeping into consideration their multifarious activities. Ergonomics contributes to designing and evaluation of task, products, environment and system in order to make them compatible with the needs, abilities and limitations of homemakers. Besides most of the women are not aware of ergonomic design of kitchen. Keeping these rational in mind the study was conducted in Muzaffarpur district of Bihar State. The main purpose of this research is to evaluate the various kitchen design in both rural and urban areas for work effectiveness. Various parameters viz., physiological, cardio-vascular, energy expenditure and perceived exertion were taken for ergonomic evaluation of kitchen design. The study analysed the working counter i.e. counter height, counter width, counter depth and kitchen size. The analysis of results indicated that a majority of respondents $(40 \%)$ had their kitchen size $10 \times 12$ feet to 12 x14 feet in rural areas, while in urban area maximum respondents $(50 \%)$ possessed their kitchen size below $6 \times 8$ feet which is smaller than the standard size $(8 \times 10$ feet $)$ of the kitchen. In case of rural areas a large majority of respondents $(90 \%)$ had their open shelves for their storage provisions which needs improvement in kitchen design, while in urban area respondents $(66.70 \%)$ had cupboards for storage of items in their kitchen. In rural area maximum respondents $(80 \%)$ had their cooking counter height between $15-45 \mathrm{~cm}$ and in urban area only half of the respondents had their cooking counter height $15-45 \mathrm{~cm}$. In rural area's majority of respondents $(40 \%)$ had their cooking counter width between $15-25 \mathrm{~cm}$, whereas in urban area maximum respondents $(43.30 \%)$ had their cooking counter width $85-125 \mathrm{~cm}$.

KEY WORDS: Ergonomics, Work effectiveness, Kitchen size, Storage, Cooking counter

- HOW TO CITE THIS PAPER : Parveen, Nikhat and Kala, Shishir (2019). Ergonomic evaluation of rural and urban kitchen design of Muzaffarpur district in Bihar. Asian J. Home Sci., 14 (1) : 28-31, DOI: 10.15740/HAS/AJHS/14.1/28-31. Copyright@ 2019: Hind Agri-Horticultural Society. 